Essential Cardiology 

Clive Rosendorff

Editor

Essential Cardiology

Principles and Practice

Third Edition

算 Springer 
Editor

Clive Rosendorff, MD, PhD, DScMed, FRCP,

FACC, FAHA

Department of Medicine

The Mount Sinai School of Medicine

The James J. Peters VA Medical Center

Bronx, NY, USA

ISBN 978-1-4614-6704-5

ISBN 978-1-4614-6705-2 (eBook)

DOI 10.1007/978-1-4614-6705-2

Springer New York Heidelberg Dordrecht London

Library of Congress Control Number: 2013941371

(C) Springer Science+Business Media New York 2013

This work is subject to copyright. All rights are reserved by the Publisher, whether the whole or part of the material is concerned, specifically the rights of translation, reprinting, reuse of illustrations, recitation, broadcasting, reproduction on microfilms or in any other physical way, and transmission or information storage and retrieval, electronic adaptation, computer software, or by similar or dissimilar methodology now known or hereafter developed. Exempted from this legal reservation are brief excerpts in connection with reviews or scholarly analysis or material supplied specifically for the purpose of being entered and executed on a computer system, for exclusive use by the purchaser of the work. Duplication of this publication or parts thereof is permitted only under the provisions of the Copyright Law of the Publisher's location, in its current version, and permission for use must always be obtained from Springer. Permissions for use may be obtained through RightsLink at the Copyright Clearance Center. Violations are liable to prosecution under the respective Copyright Law.

The use of general descriptive names, registered names, trademarks, service marks, etc. in this publication does not imply, even in the absence of a specific statement, that such names are exempt from the relevant protective laws and regulations and therefore free for general use.

While the advice and information in this book are believed to be true and accurate at the date of publication, neither the authors nor the editors nor the publisher can accept any legal responsibility for any errors or omissions that may be made. The publisher makes no warranty, express or implied, with respect to the material contained herein.

Printed on acid-free paper

Springer is part of Springer Science+Business Media (www.springer.com) 


\section{Preface to the Third Edition}

This third edition reflects the very rapid advances that have been made in our understanding and management of cardiovascular disease since the first (2001) and second (2005) editions. All of the chapters from the second edition have been extensively reviewed and rewritten. There are new chapters on Cardiovascular Disease in Women, Diabetes and the Cardiovascular System, and Cardiovascular Disease in Cancer Patients, reflecting an increasing awareness of the special features and needs of these populations. With the very rapid developments in the molecular and cell biology of cardiovascular disease, the previous chapter on Cardiovascular Gene and Cell Therapy has been split into separate chapters on Cardiovascular Gene Therapy and Cardiovascular Cell Therapy. Otherwise, the general format of the second edition has been retained, to include sections on epidemiology, cardiovascular function, examination and investigation of the patient, disorders of rhythm and conduction, heart failure, congenital heart disease, coronary artery disease, valvular heart disease, hypertension, other conditions affecting the heart (cardiomyopathies and myocarditis, pericardial disease, pulmonary vascular disease, diseases of the aorta), and special populations (women, pregnancy, elderly, renal disease, diabetes, cancer) and miscellaneous (preventive cardiology, peripheral vascular disease, preoperative assessment, gene therapy, cell therapy).

I am very happy to welcome Drs. Ralph B. D'Agostino, Rhian M. Touyz, Mark Crowther, Patrick T. O'Gara, Bruce B. Lerman, Francis E. Marchlinski, Martin R. Cowie, Michael A. Gatzoulis, John M. Canty, Jr., Arthur S. Leon, Ronald Victor, Bernhard Maisch, Nanette K. Wenger, Jolien W. Roos-Hesselink, Jorge Plutzky, Edward T. H. Yeh, and Piero Anversa as new senior authors. My thanks to all contributors for their part in producing an outstanding learning resource.

I also wish to acknowledge my assistant Indrawattie Naipal, the production editor Michael D. Sova, and the editorial, production, and composition departments of Springer, for their encouragement and hard work. 



\section{Preface to the First Edition}

"A big book," said Callimachus, the Alexandrian poet, "is a big evil!" Not always. There are some excellent, very big encyclopedias of cardiology, wonderful as works of reference. There are also many small books of cardiology, "handbooks" or "manuals," which serve a different purpose, to summarize, list, or simplify. This book is designed to fill a large gap between these extremes, to provide a textbook that is both substantial and readable and compact and reasonably comprehensive, and to provide an intelligent blend of molecular, cellular, and physiologic concepts with current clinical practice.

A word about the title. "Essential" is used here not in the sense of indispensable or absolutely required in all circumstances, for there is much more here than the generalist needs in order to practice good medicine, especially if there is easy access to a cardiology consultant. Rather, the word as used here denotes the essence or distillation or fundamentals of the mechanisms and practice of cardiology. The Principles and Practice subtitle affirms the idea that theory without a practical context may be academically satisfying but lacks usefulness, and practice without theory is plumbing. Good doctors understand the basic science foundation of what they do with patients, and great doctors are those who, as researchers or as teachers, see new connections between the basic sciences and clinical medicine.

I have been very fortunate to be able to assemble a team of great doctors who are outstanding physicians and scientists, most of them internationally recognized for their leadership position in their areas of specialization. They represent a careful blend of brilliance and experience, and, most of all, they all write with the authority of undoubted experts in their fields. They have all been asked to write up-to-date reviews of their respective areas of expertise, at a level that will be intelligible to noncardiologists as well as cardiologists, medical students, internal medicine residents, general internists, and cardiology fellows. I believe that they have succeeded brilliantly, and I know that they are all very proud to have participated as authors in this project. I am deeply grateful to all of them for the care and enthusiasm with which they carried out this task.

The organization of the book reflects pretty much the key issues that concern cardiologists and other internists at present; I have no doubt that the field will develop and change in time so that many of the modes of diagnosis and therapy described here will become much more prominent (such as gene therapy), while others may diminish or even disappear. This is what later editions of textbooks are for.

Clive Rosendorff, MD, PhD, DScMed, FRCP, FACC, FAHA 



\section{Contents}

1 Multivariable Evaluation of Candidates for Cardiovascular

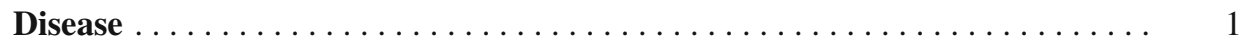

Ralph B. D'Agostino Sr. and William B. Kannel

2 Molecular and Cellular Basis of Myocardial Contractility. .............. 19 Arnold M. Katz

3 Ventricular Function. . . . . . . . . . . . . . . . . . . . . . . . 31

Lionel H. Opie

4 Vascular Function . . . . . . . . . . . . . . . . . . . . . . . . 45

Rhian M. Touyz, Augusto C. Montezano, and Clive Rosendorff

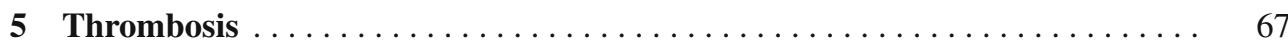

Farzana R. Bacchus and Mark Crowther

6 The History and Physical Examination of the Cardiovascular System. . . . . . 79 Rajat Gupta and Patrick O'Gara

$7 \quad$ Electrocardiography . . . . . . . . . . . . . . . . . . . . . . . 95

Tara L. DiMino, Alexander Ivanov, James F. Burke, and Peter R. Kowey

8 Echocardiography. . . . . . . . . . . . . . . . . . . . . . . . . . 113

Daniel G. Blanchard and Anthony N. DeMaria

9 Exercise Testing. . . . . . . . . . . . . . . . . . . . . . . . . . . . . 139

Abhimanyu (Manu) Uberoi, Shirin Zarafshar, and Victor Froelicher

10 Radiology of the Heart . . . . . . . . . . . . . . . . . . . . . . . . . . . . . . . 153

Christopher M. Walker, Gautham P. Reddy, and Robert M. Steiner

11 Cardiac Catheterization . . . . . . . . . . . . . . . . . . . . . . . . . . . . . . . . . . 167

Nirat Beohar, Mark J. Ricciardi, and Charles J. Davidson

12 Nuclear Imaging in Cardiovascular Medicine . . . . . . . . . . . . . . . . 195

Diwakar Jain and Barry L. Zaret

13 Cardiovascular Magnetic Resonance and Multidetector Computed Tomography ................................ 22

Gabriel Vorobiof, Norman Elliot Lepor, Mark Doyle,

Hee-Won Kim, and Gerald M. Pohost

14 Choosing Appropriate Imaging Techniques. . . . . . . . . . . . . . . . . . . . . . 249

Martin E. Goldman and Anthony F. Yu

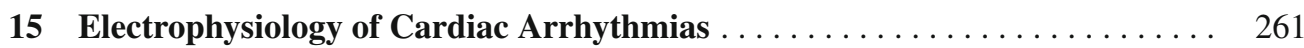

Sei Iwai, Steven M. Markowitz, and Bruce B. Lerman

16 Treatment of Cardiac Arrhythmias . . . . . . . . . . . . . . . . . . . . . . 277

Suraj Kapa and Francis E. Marchlinski 


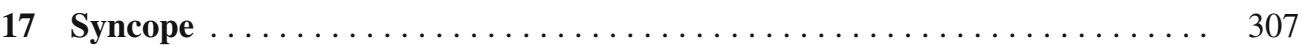

Venkata Krishna Puppala, Scott Sakaguchi, Oana Dickinson, and David G. Benditt

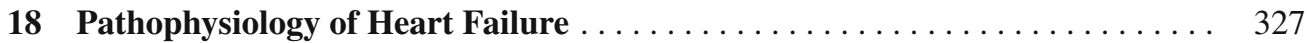

Martin R. Cowie and Philip A. Poole-Wilson

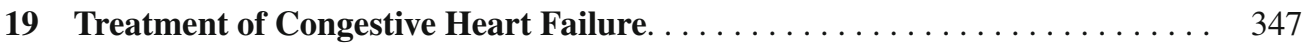

Stephen S. Gottlieb

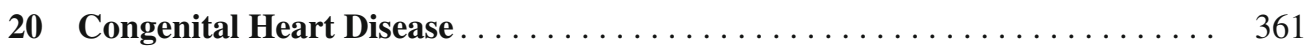

Matina Prapa, Dimitra Krexi, Anselm Uebing,

and Michael A. Gatzoulis

21 Pathogenesis of Atherosclerosis . . . . . . . . . . . . . . . . . . . . . . 377

Prediman K. Shah

22 Coronary Blood Flow and Myocardial Ischemia . . . . . . . . . . . . . . . . . . 387

Brian R. Weil and John M. Canty Jr.

23 Risk Factors and Prevention, Including Hyperlipidemia . . . . . . . . . . . 405

Antonio M. Gotto Jr. and John A. Farmer

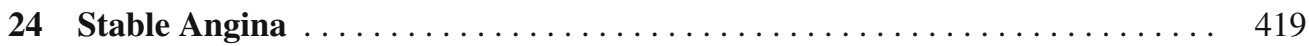

Sachin Mehta and Neal Kleiman

25 Unstable Angina and Non-ST Segment Elevation

Myocardial Infarction (Acute Coronary Syndromes) . . . . . . . . . . . . . . . 439

Sachin Mehta and Neal Kleiman

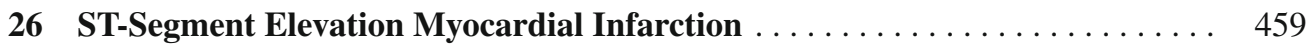

Jonathan R. Enriquez and James A. de Lemos

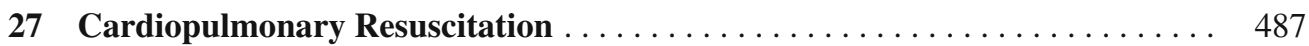

Joseph P. Ornato

28 Cardiac Rehabilitation and Secondary Prevention After Acute MI . . . . . . . . 495 Arthur S. Leon

29 Rheumatic Fever and Valvular Heart Disease . . . . . . . . . . . . . . . 505

Blanche J. Cupido and Patrick J. Commerford

30 Infective Endocarditis. . . . . . . . . . . . . . . . . . . . . . . . . . . . 521

Adolf W. Karchmer

31 Hypertension: Mechanisms and Diagnosis. . . . . . . . . . . . . . . . . 543

Clive Rosendorff

32 Hypertension Therapy . . . . . . . . . . . . . . . . . . . . . . . . 561

Norman M. Kaplan, Odelia Cooper, and Ronald G. Victor

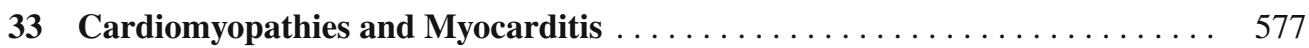

Colleen M. Harrington and Edward K. Kasper

34 Pericardial Disease . . . . . . . . . . . . . . . . . . . . . . . . . . . . . . . . . . . . 589

Bernhard Maisch

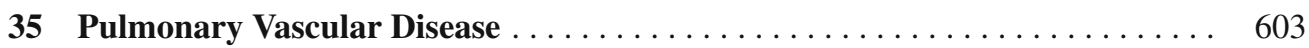

Eoin P. Judge, Dermot O'Callaghan, and Sean P. Gaine

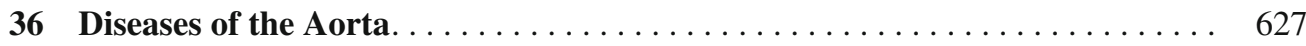

David M. Dudzinski and Eric M. Isselbacher 
37 Cardiovascular Disease in Women . . . . . . . . . . . . . . . . . . . . . . . . 639 Benjamin D. Mackie and Nanette Kass Wenger

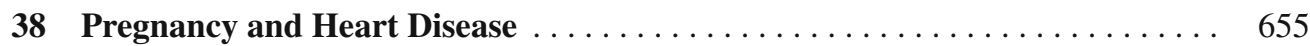
T.P.E. Ruys, Mark R. Johnson, and J.W. Roos-Hesselink

39 Heart Disease in the Elderly. . . . . . . . . . . . . . . . . . . . . . . . . . . 669 Michael W. Rich

40 Cardiovascular Complications in Patients with Renal Disease . . . . . . . . . 687 Sheldon W. Tobe, Haowei (Linda) Sun, and Murray Epstein

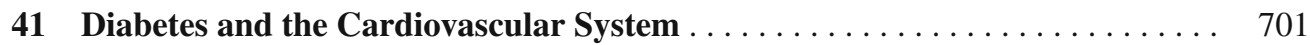
Paul Cohen and Jorge Plutzky

42 Cancer Therapy-Induced Cardiomyopathy . . . . . . . . . . . . . . . . . . . . . 715 Peter Kim, Pimprapa Vejpongsa, and Edward T.H. Yeh

43 Assessment of Patients with Heart Disease for Fitness for Noncardiac Surgery

Lee A. Fleisher and Joseph S. Savino

44 Cardiovascular Gene Therapy.

Thomas J. LaRocca and Roger J. Hajjar

45 Cardiovascular Cell Therapy. Annarosa Leri, Jan Kajstura, Marcello Rota, and Piero Anversa

46 Preventive Cardiology 767 Temilolu O. Aje and Michael Miller

47 Peripheral Arterial Disease 781 Giovina Lara Bomba and Jonathan L. Halperin

Index 



\section{Contributors}

Temilolu O. Aje, MD, MPH Division of Cardiology, Department of Medicine, University of Maryland, Baltimore, MD, USA

Piero Anversa, MD Division of Cardiovascular Medicine, Departments of Anesthesia and Medicine, Brigham and Women's Hospital, Boston, MA, USA

Farzana R. Bacchus, MD Department of Medicine, University of Toronto, Toronto, ON, Canada

David G. Benditt, MD Department of Medicine, Cardiac Arrhythmia Center, University of Minnesota Medical School, Minneapolis, MN, USA

Nirat Beohar, MD, FACC, FSCAI Division of Cardiology at Mount Sinai Medical Center, Department of Cardiology, Columbia University, Miami Beach, FL, USA

Daniel G. Blanchard, MD Division of Cardiovascular Medicine, UCSD Sulpizio Cardiovascular Center, San Diego Medical Center, University of California, La Jolla, CA, USA

Giovina Lara Bomba, MD Department of Cardiology, The Mount Sinai Hospital, New York, NY, USA

James F. Burke, MD, FACC Division of Cardiovascular Disease, Lankenau Medical Center, Wynnewood, PA, USA

John M. Canty Jr., MD Department of Medicine/Cardiovascular Medicine, University at Buffalo, Buffalo, NY, USA

Paul Cohen, MD, PhD Cardiovascular Medicine, Brigham and Women's Hospital, Harvard Medical School, Boston, MA, USA

Patrick J. Commerford, MB, ChB, FCP (SA), FACC Cardiac Clinic, Department of Medicine, University of Cape Town and Groote Schuur Hospital, Cape Town, Western Cape, South Africa

Odelia Cooper, MD Division of Endocrinology, Diabetes, and Metabolism, Cedars-Sinai Medical Center, Los Angeles, CA, USA

Martin R. Cowie, MD, MSc, FRCP, FRCP (Ed), FESC Clinical Cardiology, National Heart and Lung Institute, Imperial College London (Royal Brompton Hospital), London, UK

Mark Crowther, MD Faculty of Health Sciences, St Joseph's Hospital, McMaster University, Hamilton, ON, Canada

Blanche J. Cupido, MB, ChB, FCP (SA) Cardiac Clinic, Department of Medicine, University of Cape Town and Groote Schuur Hospital, Cape Town, Western Cape, South Africa 
Ralph B. D'Agostino Sr., PhD Department of Mathematics and Statistics, Boston University, Boston, MA, USA

Charles J. Davidson, MD Department of Medicine, Northwestern Memorial Hospital, Chicago, IL, USA

James A. de Lemos, MD Department of Cardiology, UT Southwestern Medical Center, Dallas, TX, USA

Anthony N. DeMaria, MD Division of Cardiovascular Medicine, UCSD Sulpizio Cardiovascular Center, San Diego Medical Center, University of California, San Diego, CA, USA

Oana Dickinson, MD Department of Medicine, University of Minnesota, Minneapolis, MN, USA

Tara L. DiMino, MD, FACC Safety Evaluation and Risk Management, Global Clinical Safety and Pharmacovigilance, GlaxoSmithKline, Collegeville, PA, USA

Mark Doyle, PhD Department of Medicine, Allegheny General Hospital, Pittsburgh, PA, USA

David M. Dudzinski, MD, JD Departments of Cardiology and Medicine, Massachusetts General Hospital, Boston, MA, USA

Jonathan R. Enriquez, MD Department of Cardiology, University of Missouri-Kansas City, Kansas City, MO, USA

Murray Epstein, MD, FACP, FASH Division of Nephrology and Hypertension, University of Miami, School of Medicine, Miami, FL, USA

John A. Farmer, MD Department of Medicine (Cardiology), Baylor College of Medicine, Houston, TX, USA

Lee A. Fleisher, MD Department of Anesthesiology and Critical Care, Perelman School of Medicine, University of Pennsylvania, Philadelphia, PA, USA

Victor Froelicher, MD Department of Cardiovascular Medicine, Stanford University Hospital and Clinics, Stanford, CA, USA

Sean P. Gaine, MD, PhD Department of Respiratory Medicine, Mater Misericordiae University Hospital, Dublin, Ireland

Michael A. Gatzoulis, MD, PhD Adult Congenital Heart Disease, Royal Brompton Hospital, London, UK

Martin E. Goldman, MD Department of Cardiology, Mount Sinai Medical Center, New York, NY, USA

Stephen S. Gottlieb, MD Department of Medicine, University of Maryland, Baltimore, MD, USA

Antonio M. Gotto Jr., MD, DPhil Department of Medicine, Weill Cornell Medical College, New York, NY, USA

Rajat Gupta, MD Department of Cardiovascular Medicine, Brigham and Women's Hospital/Harvard Medical School, Boston, MA, USA

Roger J. Hajjar, MD Cardiovascular Research Center, Mount Sinai School of Medicine, New York, NY, USA 
Jonathan L. Halperin, MD Department of Medicine (Cardiology), Mount Sinai School of Medicine, New York, NY, USA

Clinical Cardiology Services, The Zena and Michael A. Weiner Cardiovascular Institute, The Marie-Josée and Henry R. Kravis Center for Cardiovascular Health, New York, NY, USA

Colleen M. Harrington, MD Department of Cardiology, Johns Hopkins Hospital, Baltimore, MD, USA

Eric M. Isselbacher, MD Cardiology Division, Massachusetts General Hospital, Boston, MA, USA

Alexander Ivanov, MD, FACC Department of Cardiology, Somerset Medical Center/ Robert Wood Johnson University Hospital, Somerville, NJ, USA

Sei Iwai, MD Division of Cardiology, Department of Medicine, Stony Brook University Medical Center, Stony Brook, NY, USA

Diwakar Jain, MD, FACC, FRCP, FASNC Section of Cardiology, New York Medical College, Westchester Medical Center, Valhalla, NY, USA

Mark R. Johnson, MBBS, PhD, MRCOG, MRCP Department of Obstetrics and Gynecology, Chelsea and Westminster Hospital, Imperial College School of Medicine, London, UK

Eoin P. Judge, MD Department of Respiratory Medicine, Mater Misericordiae University Hospital, Dublin, Ireland

Jan Kajstura, PhD Division of Cardiovascular Medicine, Departments of Anesthesia and Medicine, Brigham and Women's Hospital, Boston, MA, USA

William B. Kannel, MD, MPH, FACC (Deceased) Department of Medicine and Public Health, Framingham Study/Boston University School of Medicine, Framingham, MA, USA

Suraj Kapa, MD Department of Cardiac Electrophysiology, Hospital of the University of Pennsylvania, Philadelphia, PA, USA

Norman M. Kaplan, MD Department of Cardiology, UT Southwestern Medical School, Dallas, TX, USA

Adolf W. Karchmer, MD Medicine/Infectious Disease Division, Beth Israel Deaconess Medical Center, Boston, MA, USA

Edward K. Kasper, MD, FACC, FAHA Department of Medicine/Cardiology, Johns Hopkins Medical Institutions, Baltimore, MD, USA

Arnold M. Katz, MD, DMed (Hon) University of Connecticut School of Medicine, Dartmouth Medical School, Harvard Medical School, Norwich, VT, USA

Hee-Won Kim, PhD Department of Radiology, University of Southern California, Los Angeles, CA, USA

Peter Kim, MD Department of Cardiology, The University of Texas, MD Anderson Cancer Center, Houston, TX, USA

Neal Kleiman, MD, FACC Cardiac Catheterization Laboratories, The Methodist Debakey Heart and Vascular Center, Houston, TX, USA

Department of Medicine, Weill Cornell Medical College, New York, NY, USA 
Peter R. Kowey, MD, FACC, FAHA, FHRS Division of Cardiovascular Disease, Lankenau Medical Center, Wynnewood, PA, USA

Dimitra Krexi, MD Adult Congenital Heart Disease, Royal Brompton Hospital, London, UK

Thomas J. LaRocca, MD, PhD Department of Pediatrics, University of California, San Francisco, CA, USA

Arthur S. Leon, MS, MD Laboratory of Physiological Hygiene and Exercise Science, School of Kinesiology, University of Minnesota, Minneapolis, MN, USA

Norman Elliot Lepor, MD Cedars-Sinai Heart Institute, Beverly Hills, CA, USA

Annarosa Leri, MD Division of Cardiovascular Medicine, Departments of Anesthesia and Medicine, Brigham and Women's Hospital, Boston, MA, USA

Bruce B. Lerman, MD Division of Cardiology, Department of Medicine, Cornell University Medical Center, New York Presbyterian Hospital, New York, NY, USA

Benjamin D. Mackie, MD Department of Medicine (Cardiology), Emory University School of Medicine, Atlanta, GA, USA

Bernhard Maisch, MD, PhD Department of Internal Medicine and Cardiology, University Hospital Marburg (UKGM GmbH), Marburg, Hessia, Germany

Francis E. Marchlinski, MD Division of Cardiovascular Medicine, EPS Division, Department of Medicine, Hospital of the University of Pennsylvania, Philadelphia, PA, USA

Steven M. Markowitz, MD Division of Cardiology, Department of Medicine, Cornell University Medical Center, New York Presbyterian Hospital, New York, NY, USA

Sachin Mehta, MD Department of Cardiology, Baylor College of Medicine, Houston, TX, USA

Michael Miller, MD Division of Cardiology, Department of Medicine, University of Maryland, Baltimore, MD, USA

Augusto C. Montezano, PhD Institute of Cardiovascular and Medical Sciences, BHF Glasgow Cardiovascular Research Centre, University of Glasgow, Glasgow, UK

Dermot O'Callaghan, MD Department of Respiratory Medicine, Mater Misericordiae University Hospital, Dublin, Ireland

Patrick O'Gara, MD Cardiovascular Department, Brigham and Women's Hospital/Harvard Medical School, Boston, MA, USA

Lionel H. Opie, MD, DPhil, DSc Department of Medicine, Hatter Institute for Cardiovascular Research in Africa, University of Cape Town, Cape Town, South Africa

Joseph P. Ornato, MD, FACP, FACC, FACEP Department of Emergency Medicine, Virginia Commonwealth University, Richmond, VA, USA

Jorge Plutzky, MD Cardiovascular Medicine, Brigham and Women's Hospital, Harvard Medical School, Boston, MA, USA

Gerald M. Pohost, MD, FAHA, FACC Department of Radiology, Keck School of Medicine, University of Southern California, Beverly Hills, CA, USA

Department of Medicine, School of Medicine, Loma Linda University, Beverly Hills, CA, USA

Philip A. Poole-Wilson, MD, FRCP, FESC, FACC (Deceased) Department of Cardiac Medicine, National Heart and Lung Institute, Imperial College London, London, UK 
Matina Prapa, MD Adult Congenital Heart Disease, Royal Brompton Hospital, London, UK

Venkata Krishna Puppala, MD, MPH Department of Medicine, Healtheast Care System, Minneapolis, MN, USA

Gautham P. Reddy, MD, MPH Department of Radiology, University of Washington Medical Center, Seattle, WA, USA

Mark J. Ricciardi, MD Department of Internal Medicine, University of New Mexico Hospital, Albuquerque, NM, USA

Michael W. Rich, MD Cardiovascular Division, Washington University School of Medicine, St. Louis, MO, USA

J.W. Roos-Hesselink, MD, PhD Department of Cardiology, Erasmus MC, Rotterdam, The Netherlands

Clive Rosendorff, MD, PhD, DScMed, FRCP, FACC, FAHA Department of Medicine, The Mount Sinai School of Medicine, The James J. Peters VA Medical Center, Bronx, NY, USA

Marcello Rota, PhD Division of Cardiovascular Medicine, Departments of Anesthesia and Medicine, Brigham and Women's Hospital, Boston, MA, USA

T.P.E. Ruys, MD Department of Cardiology, Erasmus Medical Center, Rotterdam, The Netherlands

Scott Sakaguchi, MD Department of Medicine, University of Minnesota, Minneapolis, MN, USA

Joseph S. Savino, MD Department of Anesthesia and Critical Care, Perelman School of Medicine, University of Pennsylvania, Philadelphia, PA, USA

Prediman K. Shah, MD Division of Cardiology, Cedars Sinai Heart Institute, Los Angeles, CA, USA

Robert M. Steiner, MD Department of Radiology, Temple University Health System, Philadelphia, PA, USA

Haowei (Linda) Sun, MD Department of Medicine, Sunnybrook Health Sciences Centre, Toronto, ON, Canada

Sheldon W. Tobe, MD, MScCH (HPTE), FRCP (C), FACP, FASH Department of Medicine, Sunnybrook Health Sciences Centre, Toronto, ON, Canada

Rhian M. Touyz, BSc (Hons), MSc (Med), PhD, MBBCh Institute of Cardiovascular and Medical Sciences, BHF Glasgow Cardiovascular Research Centre, University of Glasgow, Glasgow, UK

Abhimanyu (Manu) Uberoi, MD, MS Department of Cardiovascular Medicine, Stanford University Hospital and Clinics, Stanford, CA, USA

Anselm Uebing, MD, PhD Adult Congenital Heart Disease, Royal Brompton Hospital, London, UK

Pimprapa Vejpongsa, MD Department of Cardiology, The University of Texas, MD Anderson Cancer Center, Houston, TX, USA

Ronald G. Victor, MD Department of Medicine, The David Geffen School of Medicine at UCLA, Los Angeles, CA, USA

Gabriel Vorobiof, MD, FACC Department of Medicine, David Geffen School of Medicine at UCLA, Los Angeles, CA, USA 
Christopher M. Walker, MD Department of Radiology, University of Washington, Kent, WA, USA

Brian R. Weil, PhD Department of Medicine/Cardiovascular Medicine, University at Buffalo, Buffalo, NY, USA

Nanette Kass Wenger, MD, MACC, MACP, FAHA Department of Medicine (Cardiology), Emory University School of Medicine, Atlanta, GA, USA

Edward T.H. Yeh, MD Department of Cardiology, The University of Texas, MD Anderson Cancer Center, Houston, TX, USA

Anthony F. Yu, MD Department of Cardiology, Mount Sinai Medical Center, New York, NY, USA

Shirin Zarafshar, MD Department of Internal Medicine, Stanford University Hospital and Clinics, Stanford, CA, USA

Barry L. Zaret, MD, FACC Section of Cardiology, Yale University School of Medicine, New Haven, CT, USA 